Journal Home Page:

http://perlinguam.journals.ac.za

\section{Per Linguam}

A Journal for Language Learning Tydskrif vir Taalaanleer

\title{
PROBING THE DEPTHS: CAN BOTH SIZE AND DEPTH OF PRODUCTIVE VOCABULARY PREDICT ACADEMIC PERFORMANCE?
}

\author{
Ruth Scheepers \\ University of South Africa
}

This study investigates the link between breadth (or size) and depth of vocabulary knowledge, and the relationship between the latter and academic proficiency. Breadth of vocabulary knowledge was measured using a productive version of the Vocabulary Levels Test (Laufer \& Nation, 1995), while depth was operationalised by productive knowledge of collocations. A small sample of 60 university students of English whose examination scores were closest to the $25^{\text {th }}$, $50^{\text {th }}$ and $75^{\text {th }}$ percentiles was selected. Relationships were determined between breadth of vocabulary knowledge and depth of vocabulary knowledge on the one hand, and between depth of vocabulary knowledge and academic proficiency (represented by examination scores) on the other. While a relationship between breadth and depth of vocabulary knowledge was found, suggesting a link between smaller vocabulary size and the production of deviant multiword units for the group as a whole, the relationship between depth of vocabulary knowledge and academic performance was not proved conclusively. It should, however, be kept in mind that numbers were relatively small. Further investigations using larger samples might find a more robust relationship.

\section{INTRODUCTION}

Research over the last few decades has shown the importance of vocabulary knowledge in the language of learning and teaching to success at university, that is, academic performance (Cooper, 1999, 2000; Morris \& Cobb, 2004; Nation, 1993; Nizonkiza \& Van Dyk, 2015; Qian, 2002; Schmitt, Schmitt \& Clapham, 2001). Much of this research has focused on the influence of vocabulary knowledge on reading skills, and has in many cases used measures of vocabulary size or vocabulary depth and, less often, both (see Akbarian, 2010; Qian, 2002).

The size of a learner's ${ }^{1}$ vocabulary knowledge is traditionally measured by testing single worditem knowledge - receptive or productive, and using tests such as Nation's (1993) Vocabulary Levels Test (VLT) or versions of this (Laufer \& Nation, 1995, 1999). Depth of vocabulary knowledge is more difficult to measure as it is made up of several aspects or dimensions of word knowledge, which are sometimes difficult to isolate. Read (2004: 211) refers to vocabulary depth as comprehensive word knowledge - knowledge of a word which includes not only its semantic features but also its orthographic, phonological, morphological, syntactic, collocational and pragmatic characteristics. As yet, no single instrument has been devised to test all these aspects of word knowledge together, and researchers have focused on particular aspects only: in this regard, collocations have in recent years received increasing attention in research studies (Nassaji, 2004; Nizonkiza, Van Dyk \& Louw, 2013; Qian, 2002; Shin \& Nation, 2008) as one aspect of deep word knowledge that can be fairly successfully tested. Collocations are an important part of 
language for L2 learners in higher education contexts, as academic success requires not only word comprehension but also, more importantly, language production, especially fluency as demonstrated in collocation use (Van Dyk, Louw, Nizonkiza \& Van De Poel, 2016: 67). As Gledhill (2000: 5) observes and Laufer and Waldman (2011) and Van Dyk et al. (2016: 70) confirm, 'it is impossible for a writer to be fluent without a thorough knowledge of the phraseology ${ }^{2}$ of the particular field he or she is writing in'.

This investigation was thus motivated by the importance of fluent, idiomatic writing for academic study. Being able to write well in academic contexts requires breadth and depth of vocabulary knowledge (Hancioğlu, Neufeld \& Eldridge, 2008; Qian, 1998; Read, 2004, 2007): that is, the size of one's vocabulary, or the number of words one recognises, as well as the depth of this knowledge, which includes knowing which words typically keep company with which, that is, their collocations.

Two research questions drove this investigation:

1. What is the relationship between the size of students' productive vocabulary and the depth of their vocabulary knowledge (operationalised by their production of selected multiword units (MWUs) comprising verb+noun collocations)?

2. What is the relationship between students' depth of vocabulary knowledge (operationalised by their production of selected MWUs) and their academic performance?

\section{WHAT RESEARCH REVEALS ABOUT RELATIONSHIPS BETWEEN VOCABULARY SIZE, VOCABULARY DEPTH AND ACADEMIC PERFORMANCE}

Research over the last three decades has shown the importance of a sound knowledge of the language of instruction for learners' academic performance. By the time they reach university, students should have not only a good receptive command of the vocabulary of this language, in order to read and understand the literature in their discipline, but also a productive command of the language to allow them to master the writing of academic essays, articles, dissertations and theses (Paquot, 2010: 1). A great many studies have investigated the effect of vocabulary knowledge on reading skills, in most cases using measures of vocabulary size (Laufer, 1992; Laufer \& Ravenhorst-Kalovski, 2010; Nation, 2006; Nation \& Waring, 1997; Staehr, 2008) or vocabulary depth (Qian, 1998; Qian \& Schedl, 2004), and less often both (Qian, 2002).

Nation (1993) argues that skill in language use, which includes reading comprehension, is dependent on vocabulary size and is vital for success at university. As it grows, this skill allows for a growth in knowledge of the world through the competent use of language. If this knowledge is to increase, vocabulary must also increase. Tests of vocabulary size such as the VLT treat vocabulary as a trait, a mental characteristic of a learner that can be described and measured, using individual word items in a limited context (Laufer \& Nation, 1999; Qian, 2002; Qing, 2009; Read, 2004). In contrast, the trend in research on depth of vocabulary knowledge has been for researchers to investigate the quality of vocabulary knowledge by focusing on specific aspects of word knowledge, possibly because it is very difficult to measure all aspects of what it is to 'know' a word. To this end, corpus investigations, founded on an interactionist view of 
vocabulary, one which assesses learners' ability to use the words they know appropriately in particular contexts (Read, 2007: 115), have been used increasingly in research. Studies investigating depth of vocabulary knowledge, using corpus techniques or otherwise, have dealt with aspects such as collocational knowledge (Bahns \& Eldaw, 1993; Nesselhauf, 2003, 2005; Nizonkiza et al., 2013; Nizonkiza \& Van De Poel, 2016; Qian, 2002; Scheepers, 2014, 2017), derivational knowledge (Schmitt \& Zimmerman, 2002), and knowledge of polysemy and synonymy (Qian, 2002).

A number of studies have investigated students' vocabulary knowledge and the link this has to their academic success (Cooper, 1999; Milton \& Treffers-Daller, 2011, 2013; Nation, 2006; Qian, 1998, 2002; Schmitt et al., 2001: 56). Several of these have focused on vocabulary size, that is, the number of words students need to know in order to succeed at university. One such study in the South African context was conducted by Cooper (1999, 2000). In this country, many students entering university have low reading levels and a vocabulary that is not adequate for the tasks of academic reading and writing (Meier, 2011; Pretorius, 2002). In her study, for example, Cooper $(1999,2000)$ found that there was a relationship between the breadth (size) of first-level ESL (English as a Second Language) university students' vocabulary knowledge and their academic performance: weaker students had small receptive vocabularies and lacked knowledge of lower-frequency (academic) words, lacking both the high-frequency word knowledge and the knowledge of academic vocabulary to cope with academic texts (Cooper, 1999; 2000: 28). Their 'overall grasp' of academic vocabulary was not adequate in meeting the lexical demands of their reading at university level (Cooper, 2000: 19), and almost half (45\%) of the students who failed the academic vocabulary test failed the year (Cooper, 1999: 88).

In a similar vein, Morris and Cobb (2004) used VocabProfiler (Cobb, 2000) to analyse the vocabulary and predict the linguistic and academic ability of Canadian TESL (Teaching English as a Second Language) trainees. These students came from a variety of L1 backgrounds but had native-like or near native-like proficiency in spoken English and were highly proficient writers of English. Using a corpus comprising their students' entrance examination essays, Morris and Cobb (2004) established students' vocabulary profiles. In order to measure their academic success, they used these students' marks on two compulsory grammar courses, G1 (an introduction to English grammar focusing on knowing that, or declarative knowledge) and G2, the second pedagogical grammar course focusing on knowing how (Morris \& Cobb, 2004: 81).

From a correlation of all the vocabulary profile scores of these students with their academic grades, Morris and Cobb (2004) established the percentage of coverage of students' texts (that is, the percentage of words used from each word level) that resulted in academic success: a score on the first thousand words of at least 85\%, a score on the Academic Word List (AWL) (Coxhead, 2000 ) of over $5 \%$, and a score on function words of over $50 \%$. The native speakers (NSs) in the control group outperformed the non-native speakers (NNSs) on every comparison, achieving higher marks and using fewer words from the first thousand level and function words, and more from the AWL (Morris \& Cobb, 2004: 82-3). According to this standard, Morris and Cobb deduced that NNSs were 50\% less likely to do as well as NSs (2004: 83); fewer than half the group of NNSs (46\%) achieved the ideal profile on the AWL, suggesting that academic words present a particular stumbling block to ESL learners. 
In a study with Iranian university students, Bahramlou and Yazdani (2013) also investigated whether vocabulary profiles could be used to predict academic achievement. They used students' grades (GPAs or grade point averages), writing scores and reading scores as measures of academic success. They assessed the proficiency levels of their students (English Literature and English Translation students at an Iranian university) using the Michigan Test of English Language Proficiency. VocabProfile (Cobb, 2000) was used to establish students' vocabulary profiles. They then used receptive and productive versions of the VLT (Laufer \& Nation, 1995) to validate these profiles. They subsequently found no significant correlations between vocabulary profiles and GPA scores, explaining this by the fact that these scores were inflated. However, they did observe 'moderate significant correlations' between students' vocabulary (lexical) profiles on the one hand and reading and writing scores on the other (Bahramlou \& Yazdani, 2013: 279). They interpreted this to mean that vocabulary profiles as a measure of vocabulary knowledge were related to and could to some degree predict performance on measures of academic achievement, although these relationships were not robust enough to support the use of vocabulary profiles alone as predictors of academic achievement.

It is often difficult to separate breadth and depth of word knowledge entirely, and most researchers see the value of testing both dimensions. Vermeer (2001), for instance, asserts that breadth and depth are closely related and that, the larger one's vocabulary, the deeper one's vocabulary knowledge is likely to be. The opposite also applies: the smaller one's vocabulary, the less likely it is that one will have developed a depth of vocabulary knowledge. Qian (2002: 517518), too, argues that both vocabulary size and depth dimensions are important in reading comprehension. He believes, as do Vermeer (2001) and others (Hazenberg \& Hulstijn, 1996; Laufer, 1991; Milton \& Treffers-Daller, 2011, 2013; Morris \& Cobb, 2004; Schmitt \& Zimmerman, 2002), that vocabulary is acquired in an incremental fashion, with those words which are acquired at the beginning of the learning process likely to be learnt in more depth than those learnt later in the process; the more words a learner knows, the deeper the knowledge of all these words is likely to be.

Depth of vocabulary knowledge is also likely to improve learners' ability to guess the meaning of unfamiliar words in context and, in this way, the two dimensions of lexical knowledge support each other (Qian 2002: 518). In a study investigating the relationship between L2 learners' depth of vocabulary knowledge and their success in deriving the meaning of words from context, Nassaji (2004: 123) found that the depth of learners' vocabulary knowledge was 'a much stronger predictor of inferencing success than the degree of strategy use': although there was a relationship between students' use of lexical inferencing strategies and success, the effects of these strategies were 'significantly mediated by the learner's depth of vocabulary knowledge'.

In his study, Qian (2002) set out to establish the contribution of vocabulary size and three aspects of vocabulary depth (synonymy, polysemy and collocation) to basic reading comprehension, using a sample of ESL students from 19 language backgrounds at the intermediate level at a Canadian university. He used four measures for this purpose: the Reading for Basic Comprehension Measure (a version of the TOEFL (Test of English as a Foreign Language) reading comprehension subtest) as the criterion measure of reading for basic comprehension (TOEFL-RBC) (Qian, 2002: 523), and three vocabulary measures as the independent predictor variables: the Depth-of-Vocabulary-Knowledge Measure (DVK), which tests depth of receptive 
English vocabulary knowledge by measuring three elements of vocabulary: synonymy, polysemy, and collocation (Qian, 2002: 524); the VLT (labelled VS) (Nation 1983), which measures vocabulary size; and the TOEFL Vocabulary Item Measure (TOEFL-VIM), which measures knowledge of English synonyms in a limited context.

Qian (2002: 531) found that scores on all three predictors (i.e., the DVK, VS and TOEFL-VIM) were 'highly intercorrelated' and although he found all three vocabulary measures to be equally useful in predicting reading performance, the DVK was superior in that it provided a greater 'positive washback' effect (Qian, 2002: 532) on teaching and learning of new vocabulary because it assessed knowledge of polysemy and collocation rather than of single meanings of target words. He suggests that using measures of depth and size of vocabulary together, rather than one or the other on their own, would increase the ability to predict reading performance (Qian, 2002: 532).

In a more recent study that relates closely to those of Qian (2002) and Vermeer (2001), Akbarian (2010) investigated whether there was a relationship between vocabulary size and vocabulary depth among Iranian postgraduates enrolled in an English for Academic Purposes (EAP) course. Using a passive version of the VLT to measure size, and Read's (1993) Word Associates Test to measure aspects of depth of vocabulary knowledge such as synonymy and collocation, he found that the two tests correlated strongly when the results for the group as a whole were calculated. In order to achieve a clearer idea of whether size and depth correlated across levels of proficiency, Akbarian also reported the results of the high and low performers in his group. This division was based on whether students had achieved mastery of the 2000-word level. Only a small portion of the group had achieved this and made up the 'high proficient' group while the remainder made up the 'low proficient' group (Akbarian, 2010: 399).

Using linear regression analysis, Akbarian found that vocabulary size was a strong predictor of vocabulary depth for the high proficient group; although there was a strong correlation between the VLT and the Word Associates Test in the low proficient group, vocabulary size was not as strongly predictive of vocabulary depth as it had been in the stronger group. In other words, just as Vermeer (2001) found, the more words students knew, the greater the depth of their vocabulary knowledge was likely to be. Akbarian (2010) argues that learners such as those in his study first learn a number of words and then begin to build up a network of knowledge about these words - but this can only occur once their vocabulary size has reached a certain level. He concludes that, "while breadth and depth of vocabulary knowledge might converge when language learners are relatively advanced, the dimensions are more distinct at lower levels of language proficiency' (Akbarian, 2010: 400).

In a recent study closer to home, Van Dyk, Louw, Nizonkiza and Van De Poel (2016) investigated the relationship between language use (in this case, the productive use of collocations) and academic literacy/proficiency, in the light of evidence of the predictive power of academic literacy for success in higher education (Van Dyk, 2005). They note that research has established a relationship between learners' vocabulary and their academic literacy (Laufer, 1997; Nation, 2001; Qian, 2002; Nizonkiza \& Van Dyk, 2015), and a number of studies have established a relationship between using collocations (productive deeper word knowledge) and 
overall linguistic proficiency (Boers, Eykmans, Kappel, Stengers \& Demecheleer, 2006; Nizonkiza, 2011).

Van Dyk et al. (2016) tested the relationship between academic literacy and knowledge of collocations of words selected from several word frequency bands to establish whether knowledge of collocations develops in tandem with academic literacy. It was hoped that this would reveal a link between academic literacy and collocations, in other words establishing whether those students who had low levels of academic literacy (measured by their scores on the Test of Academic Literacy Levels (TALL) and its Afrikaans equivalent, Toets van Akademiese Geletterdheidsvlakke or TAG) and were so-called 'at risk' students would also perform poorly on the collocation test.

Subjects in Van Dyk et al.'s (2016) study were students at a South African university enrolled in two academic literacy courses, one taught through the medium of English, and the other through Afrikaans. A test designed to measure productive knowledge of collocations (Nizonkiza, 2012) was used, with test items selected from Nation's (2006) 2000-word, 3000-word and 5000-word frequency bands, and from the AWL. Only verb-noun collocations were tested. These researchers found a moderate but significant correlation between scores on the TALL/TAG and the collocation test, suggesting that students who scored higher on the collocation test would have less risk of failing academically. This answered the main research question, the extent to which collocation knowledge (that is, as in the present study, an aspect of deep word knowledge) predicts academic literacy. They also found statistically significant correlations between scores on the TALL/TAG and collocation scores at all word frequency bands except the 2000-word band (with a correlation coefficient of .199), suggesting that mastery of collocations at each frequency band is related to academic literacy, and indicating a possible parallel growth in academic literacy and collocational knowledge. This suggests a link between growth in productive word knowledge (operationalised by collocation knowledge in Van Dyk et al.'s 2016 study and in the study discussed in this article) and growth in academic literacy (Van Dyk et al., 2016: 74). Van Dyk et al. (2016: 75) argue that these findings support the view that, while it is important that students at university understand both general and academic vocabulary, it is vital that they are also able to use these words productively; in other words, they need deep word knowledge of the words they know.

The present study sought to build on findings from these and other studies by investigating, on the one hand, the relationship between size and depth of students' vocabulary knowledge, and on the other hand, more crucially in this case, the power of depth of vocabulary knowledge (expressed in students' production of MWUs comprising verb-noun collocations) to predict academic success.

\section{METHODOLOGY}

This article reports on one phase of a larger study, for which ethical clearance was granted by the University's Ethics Committee and Dean of the College of Humanities (see Scheepers, 2014). In this phase, quantitative and qualitative methods were employed to investigate the relationship between student writers' depth of vocabulary knowledge and their vocabulary size, and the relationship between their depth of vocabulary knowledge and their academic performance. 
Wordsmith Tools Version 4 (Scott, 2008) was used to extract collocations featuring three highfrequency delexical ${ }^{3}$ verbs, have, make and take, from a corpus made up of writing by these students, and these were manually analysed for errors and deviations.

\section{Participants}

Participants were students enrolled in two modules, English Literature and English Communication for Law, at the University of South Africa (Unisa), an open distance learning institution. The total sample in the main study comprised 298 students, 139 from the Literature module and 159 from the Law module. In the main study, students' examination scripts were transcribed and compiled to form a student corpus, comprising a Literature sub-corpus and a Law sub-corpus. Students were representative of the multicultural and multilingual student body of the university and included speakers of all 11 official South African languages. The medium of instruction at this university is English and, in order to pass their degree, students must be able to read and write in English at a fairly advanced level. As most of these students would have had at least nine years, from Grade 4 to 12, of instruction through the medium of English, it was anticipated that they would fall into the 'intermediate' or 'proficient learner' category, according to performance levels established in the research done in the National Benchmark Test Project ${ }^{4}$ (2009).

\section{Procedure}

For the purposes of the phase of the study discussed here, a smaller sample was drawn from the original 298 students. This was done by using examination scores as the criterion variable: the 10 students whose scores fell closest to the $25^{\text {th }}, 50^{\text {th }}$ and $75^{\text {th }}$ percentile groups ${ }^{5}$ respectively in the Literature group and the Law group were selected, resulting in a sample of 60 students in all. This is a form of non-probability sampling (Dörnyei, 2007: 98) known as quota sampling, in which the size of the sub-groups within a particular sampling frame is defined, and the sample is then selected from the group of subjects available. This process resulted in six sub-groups, with 10 participants in each.

In the first part of the study (described in more detail in Scheepers, 2014, 2016), the productive vocabulary of the 298 students was measured by administering an active version of Laufer and Nation's (1995) VLT (Schmitt et al., 2001) in order to establish the levels of vocabulary at which they had achieved mastery, and those levels where their knowledge was still developing (for more details on this part of the study, see Scheepers 2016). Statistical Package for Social Scientists (SPSS) ver. 22 was used to perform the statistical analyses.

In order to determine whether there was a relationship between the size and depth of vocabulary knowledge of this smaller sample of 60 students, their examination texts were extracted from the corpus. Concordance lines for all word forms of each of the target words have, make and take were generated using Wordsmith Tools ver. 6 (Scott, 2008). Then all MWUs containing verbnoun collocations featuring the three verbs have, make and take were extracted from the concordance lines, and used as the operationalisation of students' depth of productive word knowledge. Once extracted, these MWUs were analysed manually for errors and the number of 
deviant MWUs and errors was calculated ${ }^{6}$ (the process is explained more fully in Scheepers, 2014, 2017).

In addressing the first research question, scores on the third and fourth levels of the VLT (the 5 000-word level and the University Word List (UWL) (Xue \& Nation, 1984)), and the total vocabulary scores of these 60 students (30 from Literature and 30 from Law), grouped according to percentile level, were compared to the number of MWUs containing collocations and errors. Correlations were performed in this phase of the analysis. In addressing the second research question, the relationship between the number of MWUs and the number of errors they contained, and students' academic performance was investigated. Correlations between the total number of MWUs, the number of deviant MWUs and the number of errors, and examination scores at each percentile level were performed on SPSS.

\section{RESULTS AND DISCUSSION}

In addressing the first research question (the relationship between size and depth of productive vocabulary), only scores on the 5000 -word level, the UWL and the total vocabulary test scores were taken into consideration. This decision was based on research that has been done in the field of vocabulary and reading: Schmitt et al. (2001: 56) note that most research suggests that knowledge of the most frequent 5000 words should provide ESL learners at academic level with enough vocabulary to read authentic texts. However, and more importantly for this study, it is commonly believed that, for learners to be able to achieve a 95\% coverage of academic texts, they also need to have knowledge of some academic words (in this case the UWL) and technical terms (Paquot, 2010: 9-10). Recent research does call for a more fine-tuned approach to vocabulary levels - Schmitt and Schmitt (2014: 494) argue, for instance, that there should be a new focus on those words between the 3000 and 9000 -word levels, which they refer to as 'midfrequency' vocabulary.

Table 1 below reflects the mean scores of this group of students (per percentile level) for the 5 000-word level, the UWL and the whole vocabulary test, the number of target MWUs in their texts, and the number and percentage of those that were deviant:

Table 1: RQ 1: Vocabulary size and MWUs

\begin{tabular}{|c|c|c|c|c|c|c|c|c|c|}
\hline & & Percentile & $\begin{array}{l}5000 \\
\text { word } \\
\text { level }\end{array}$ & UWL & $\begin{array}{l}\text { Total } \\
\text { vocab \% }\end{array}$ & $\begin{array}{l}\text { Total } \\
\text { MWUs }\end{array}$ & $\begin{array}{l}\text { Correct } \\
\text { MWUs }\end{array}$ & $\begin{array}{l}\text { Deviant } \\
\text { MWUs }\end{array}$ & Errors \\
\hline & $\mathrm{N}$ & & Mean & Mean & Mean & & & & \\
\hline Lit & 10 & $25^{\text {th }}$ & 56.9 & 60.0 & 68.3 & 31 & 25 & $6(19.4 \%)$ & 9 \\
\hline & 10 & $50^{\text {th }}$ & 65.6 & 68.9 & 68.7 & 25 & 25 & 0 & 0 \\
\hline & 10 & $75^{\text {th }}$ & 85.0 & 78.9 & 78.9 & 31 & 31 & 0 & 0 \\
\hline Law & 10 & $25^{\text {th }}$ & 44.3 & 53.9 & 50.6 & 13 & 8 & $5(38.5 \%)$ & 7 \\
\hline & 10 & $50^{\text {th }}$ & 50.0 & 56.7 & 55.9 & 8 & 5 & $3(37.9 \%)$ & 3 \\
\hline & 10 & $75^{\text {th }}$ & 57.5 & 68.3 & 66.6 & 16 & 14 & $2(12.5 \%)$ & 2 \\
\hline
\end{tabular}

Table 1 reflects that, in general, the Law students fared less well than the Literature students. With the exception of the UWL scores at the $25^{\text {th }}$ percentile, Literature students scored at least 
$10 \%$ higher than their Law counterparts at each percentile level. It is nevertheless clear that both Literature and Law students at the $25^{\text {th }}$ percentile knew fewer words than those at the $50^{\text {th }}$ and $75^{\text {th }}$ percentiles; this knowledge of words increased incrementally from the $25^{\text {th }}$ to $75^{\text {th }}$ percentile at the 5000 -word level, in the UWL and in the total score. With regard to the frequency of MWUs, there was no discernible incremental pattern, with highest and lowest percentile groups being very similar and the middle groups having lower frequencies; there was, however, a qualitative difference in their production, in that the Literature students at the $50^{\text {th }}$ and $75^{\text {th }}$ percentile levels produced no deviant MWUs.

Taking the results in Table 1 at face value, it appears that students who produced only correct MWUs were those in the Literature group who scored $65 \%$ or above at the 5000 -word level (that is, those at the $50^{\text {th }}$ and $75^{\text {th }}$ percentiles). In both groups, those students who produced deviant MWUs scored below $60 \%$ on these levels. It may be that knowledge of words at the 5000 -word level is a tipping point for the development of deeper word knowledge, as reflected in a more appropriate use of formulaic language. This would support those scholars who have stressed the importance of this level of word knowledge for reading success at academic level (Akbarian, 2010; Laufer \& Ravenhorst-Kalovski, 2010; Schmitt \& Schmitt, 2014; Schmitt et al., 2001).

In order to test whether there was a relationship between size of vocabulary and the production of MWUs (an aspect of depth of vocabulary knowledge) and specifically error-free production, Spearman's rho correlations were conducted between size of vocabulary (5 000-word level, UWL and total vocabulary score) and the percentage of deviant MWUs for the sample of 60 students as a group. The results showed modest yet significant negative correlations between different aspects of vocabulary size and inappropriate use of MWUs, as indicated in Table 2. These results suggest that, the smaller the students' vocabulary, the more likely they were to produce deviant MWUs.

Table 2: Correlations: Vocabulary scores and percentage of deviant MWUs

\begin{tabular}{|l|l|l|l|}
\hline Whole group & $\begin{array}{l}\text { \% dev } \\
\text { N=60 }\end{array}$ & $\begin{array}{l}\text { Lit } \\
\text { MWUs }\end{array}$ & $\begin{array}{l}\text { Law } \\
\mathbf{N}=\mathbf{3 0}\end{array}$ \\
\hline $\mathbf{5 0 0 0}$-word level & $-0.27^{*}$ & $-0.42^{*}$ & -0.085 \\
UWL & $-0.29^{*}$ & $-0.35^{*}$ & -0.22 \\
Total vocab\% & $-0.31^{*}$ & $-0.40^{*}$ & -0.13 \\
\hline
\end{tabular}

*Correlations significant at 0.05

When correlations were conducted for the Literature and Law groups separately, significant negative correlations ${ }^{7}$ were found only in the Literature group, between deviant MWUs and vocabulary size at the 5000 -word level, the UWL and the total vocabulary scores, as reflected in Table 2 above. This supports the suggestion that there is a relationship between vocabulary size and depth, in that students with smaller vocabularies were less likely to produce correct MWUs made up of verb-noun collocations, an aspect of depth of vocabulary knowledge. This finding is similar to Akbarian's (2010), who found that students with smaller vocabularies were less likely to develop depth of word knowledge, although it must be kept in mind that in my study both the database and the number of relevant MWUs were very small. 
In addressing the first research question, then, the findings were that the Literature students outperformed the Law students, producing marginally more MWUs relative to the number of occurrences of the three verbs at the $25^{\text {th }}$ and $50^{\text {th }}$ percentiles, though fewer than the Law students at the $75^{\text {th }}$ percentile. None of these differences were significant, however. The difference in numbers of deviant MWUs produced by the two groups was, however, revealed as being significant, with significant negative correlations suggesting a relationship between smaller vocabulary size and the production of deviant MWUs for the group as a whole. There were fewer deviations in MWU use at all three percentile levels in the Literature corpus, with no deviations at the $50^{\text {th }}$ and $75^{\text {th }}$ percentiles.

Once a relationship had been established between size and depth of vocabulary knowledge, it was important to investigate how the production of MWUs by this group of students was related to their examination scores, in order to establish a link between depth of vocabulary knowledge and academic performance. This addressed the second research question. This part of the analysis looked more closely at the relationship between academic proficiency in this sample of students (operationalised by their examination scores) and an aspect of depth of vocabulary knowledge (their production of MWUs comprising verb-noun collocations).

Several studies have shown that MWUs, particularly collocations, present obstacles to successful language learning, especially at tertiary level where students must comply with the requirements of academic genres. Nesselhauf (2003, 2004, 2005), Granger (1998), Howarth (1998), Fan (2009), Farghal and Obiedat (1995), Shirato and Stapleton (2007), Stubbs (2001), Altenberg and Granger (2001), and Laufer and Waldman (2011) have all shown the difficulties learners experience with collocations. For instance, Laufer and Waldman (2011) note the importance of delexicalised verbs such as have, make and take and their collocations in their study of verb-noun collocations in the writing of three groups of Hebrew-speaking second language learners at different proficiency levels. They found that NNSs used fewer collocations overall, using significantly fewer of these combinations than NSs, revealing that collocation posed difficulties even for advanced learners (Laufer \& Waldman, 2011: 664-665). Laufer and Waldman (2011: 648) stress the importance of MWUs, which are 'currently viewed as a necessary component of second-language (L2) lexical competence in addition to the knowledge of single words', and they underline the now commonly held view that knowledge of MWUs improves the quality, fluency and idiomaticity of language use, both spoken and written. Incorrect MWUs in students' examination answers may negatively influence the coherence of their responses, which in turn may affect the scores assigned to them by examiners (Laufer \& Waldman, 2011; Hill, 1999).

In order to explore the possibility of a relationship between students' academic performance (indicated by their scores on the module examinations) and the number of correct MWUs comprising verb-noun collocations, examination scores and frequencies of MWUs were compared per percentile level. Table 3 below reflects mean scores for the examination, the number of MWUs produced and their errors, and the percentage of deviant MWUs in this group of 60 students: 
Table 3: MWUs: total, deviant and number of errors

\begin{tabular}{|llllllll|}
\hline & Percentile & N & Exam & MWUs & $\begin{array}{l}\text { Deviant } \\
\text { MWUs }\end{array}$ & $\begin{array}{l}\text { \% Deviant } \\
\text { MWUs }\end{array}$ & Errors \\
\hline \multirow{3}{*}{ Lit } & $25^{\text {th }}$ & 10 & 45.00 & 31 & 6 & 19.4 & 9 \\
& $50^{\text {th }}$ & 10 & 53.30 & 25 & 0 & 0 & 0 \\
& $75^{\text {th }}$ & 10 & 62.20 & 31 & 0 & 0 & 0 \\
Law & $25^{\text {th }}$ & 10 & 45.90 & 13 & 5 & 38.5 & 7 \\
& $50^{\text {th }}$ & 10 & 56.80 & 8 & 3 & 37.9 & 3 \\
& $75^{\text {th }}$ & 10 & 66.00 & 16 & 2 & 12.5 & 2 \\
\hline
\end{tabular}

As in the case of the first research question, the findings from the analysis addressing the second question revealed a difference between the Literature and Law groups. Although the actual counts were low, Literature students at the $25^{\text {th }}$ percentile level in the examination produced deviant MWUs at just half the rate of the same percentile in the Law group (19\% and 38\% respectively). The remaining Literature students in this sample produced no deviant MWUs at all. Thus, there was a noticeable qualitative difference in the Literature sample, in that only the lowest percentile group produced deviant MWUs. This qualitative difference was not evident in the Law sample: the $50^{\text {th }}$ percentile group fared much the same as the $25^{\text {th }}$ percentile group, and a proportion of MWUs (12\%) was deviant even among the highest achievers in this course. So, it seems that, among the students in the Literature group in particular and to a lesser extent in the Law group, students in the higher percentile levels (those who did satisfactorily to well in their examinations) used MWUs more successfully than students who were just passing or those who, with a mark below $50 \%$, were failing.

In order to determine statistically whether there was indeed a relationship between examination scores on the one hand, and the number of deviant MWUs and the number of errors on the other, correlations were conducted. Given the small numbers in each group, a non-parametric correlation, Spearman's rho, was used. When correlations were conducted for the whole group of 60 students, there were negative correlations between examination scores and deviant MWUs $\left(r_{s}=-0.22, p=0.090\right)$ and between examination scores and errors $\left(r_{s}=-0.22, p=0.084\right)$, but these were not significant. In order to test these results further, correlations were conducted for the two groups separately. The results were much the same: in the Literature group, the correlations between examination scores and both deviant MWUs and errors were negative but not significant $\left(r_{s}=-0.24, p=0.185\right)$, and this was also the case with the results of the correlations for the Law group $\left(r_{s}=-0.32, p=0.081\right.$ and $r_{s}=-0.33, p=0.072$ for the correlation between examination, and deviant MWUs and errors respectively).

While these correlations may suggest a relationship between deviance of MWUs and their errors, and lower examination performance, there were no significant correlations and the numbers in question were very small. As such, these findings remain inconclusive, making this an area that merits further investigation.

Thus, in addressing the second research question, although findings revealed no significant relationship between this particular aspect of vocabulary depth, the production of MWUs 
comprising verb-noun collocations, and academic performance in this smaller sample, Literature students used more MWUs and, except for the weaker students at the $25^{\text {th }}$ percentile, used them correctly, while Law students used fewer MWUs and tended to use these incorrectly. This finding can be linked to those for the first research question, that students in the $25^{\text {th }}$ percentiles of both the Literature and the Law corpora knew fewer words than students in the $50^{\text {th }}$ and $75^{\text {th }}$ percentiles. This suggests an implicit link between academic performance, breadth of vocabulary knowledge and an aspect of depth of vocabulary knowledge, namely, the correct use of MWUs comprising verb-noun collocations.

\section{CONCLUSION}

This study set out to establish the existence of a relationship between a group of students' vocabulary size and the depth of their vocabulary knowledge on the one hand, and of a relationship between their depth of word knowledge, reflected in their production of MWUs comprising collocations of delexical verb+noun and their academic proficiency (operationalised by their examination scores) on the other.

The analysis revealed significant negative correlations between size of vocabulary and the production of deviant MWUs for the whole group (research question 1), suggesting that, the smaller the students' vocabulary, the poorer the depth of their vocabulary was likely to be with regard to their use of collocations; it was significant to note that students who performed at $65 \%$ or above on the 5 000-word level did not make errors in their use of MWUs. When correlations were conducted for the Literature and Law groups separately, significant but negative correlations emerged only in the Literature group. These findings support those of Akbarian (2010) who also found that students with smaller vocabularies were less likely to develop depth of word knowledge.

In answer to research question 2, when examination scores were correlated with the number of deviant MWUs and the number of errors, both for the group of 60 students as a whole and for the two groups separately, all correlations were negative, albeit not significant. Despite the small sample size and this outcome, the descriptive data did suggest that academically weaker students were more likely to produce MWUs that were deviant.

Perhaps the most important findings from this investigation concern the relationship between breadth and depth of vocabulary knowledge in the context of academic achievement. Evidence of strong relationships between breadth and depth of vocabulary knowledge, and between size of vocabulary in particular, and academic performance, have highlighted the importance of word knowledge to academic success. Although all three percentile groups from the Literature and from the Law groups achieved a mean score above mastery level of the 2000 -word level in the main study, in the phase of the study discussed here it emerged that very few in this sample of 60 had achieved mastery of the higher levels of vocabulary (5 000-word level and the UWL): only the Literature students at the $75^{\text {th }}$ percentile had achieved mastery of the 5000 -word level, and none of the students had achieved mastery of the UWL, although in the $75^{\text {th }}$ percentile the Literature group was very close to achieving this. These word levels are vital for academic success, allowing adequate comprehension of academic texts and facilitating the development of deeper word knowledge: the more words one knows, the deeper one's depth of knowledge will be 
(Qian, 2002; Vermeer, 2010). Equally significant was that most students in this sample had not developed a depth of knowledge of high-frequency words, manifested by the type of errors they made in the target MWUs, suggesting a lack of collocational knowledge of words that they did know (Scheepers, 2017), combined with a lack of knowledge of lower frequency words: in other words, deficits in both breadth and depth of vocabulary knowledge. A lack of awareness of collocational restrictions was particularly evident in the MWUs produced in the Law corpus; Farghal and Obiedat (1995: 321) similarly found that their Arabic subjects' 'unawareness of colloquial restrictions of lexical items' led them to produce deviant collocations. This suggests that knowledge of high-frequency vocabulary, while necessary, is not sufficient, and that knowing more words is more likely to lead to greater depth of vocabulary knowledge (Akbarian, 2010; Schmitt \& Zimmerman, 2002; Vermeer, 2001).

Fairly robust relationships were found between size and depth of vocabulary. As far as the two groups were concerned, Literature students performed more strongly on measures of both breadth and depth of vocabulary knowledge than their counterparts in the Law group. Although the relationship between depth of vocabulary knowledge and academic performance was not proved conclusively for the whole group or the two groups separately, it should be kept in mind that numbers were relatively small.

One main issue has emerged from the findings in this study on vocabulary breadth and depth: the need to increase vocabulary size and depth among university students such as those in this study. The challenge remains how best to do this. Students are arriving at university ill-prepared for the demands of academic reading (Meier, 2011). This is in part the result of their schooling: many schools and communities in South Africa do not have a well-entrenched culture of reading (Machet \& Tiemensma, 2009) and, without reading, vocabulary knowledge is unlikely to grow. Reading and vocabulary knowledge, both breadth and depth, feed naturally into good writing skills. This has implications for students at university; if they wish to compete in the academic milieu, they must be able to write in a way that is accurate and stylistically appropriate. Although high-frequency words are often regarded as less important than academic words, and although errors in their use may not affect communication, such errors can have a cumulative effect on students' production, affecting the quality of their writing (Lee \& Chen, 2009: 121; Laufer \& Waldman, 2011; Hill, 1999).

These findings are supportive of previous studies, confirming the link between breadth and depth of vocabulary knowledge, and showing a tentative link between vocabulary depth and academic performance. The study has also added a new dimension to these findings by investigating student writing produced in a complex, multilingual educational context, and in different courses, Literature and Law.

\section{ENDNOTES}

\footnotetext{
${ }^{1}$ In this article, 'learner' refers generally to any learner of English (or any other language) as a second language; 'student' is used to refer specifically here to ESL learners at university.

${ }^{2}$ Gledhill defines phraseology as 'the preferred way of saying things in a particular discourse', quoting Kennedy (1984, cited in Gledhill, 2000: 5).
} 
${ }^{3}$ High-frequency verbs such as have, go, do, say, take, give, get and make can be referred to as delexical verbs (Altenberg \& Granger, 2001; Howarth, 1998), because they tend to be found in combinations where the noun carries the main semantic weight of the expression and the verb is semantically empty, e.g. have a look, make a comment, take a turn.

4 'Proficient: Performance in domain areas suggests that academic performance will not be adversely affected. If admitted, students should be placed on regular programmes of study. Intermediate: Challenges in domain areas identified such that it is predicted that academic progress will be affected. If admitted, students' educational needs should be met in a way deemed appropriate by the institution (e.g. extended or augmented programmes, special skills provision)' (National Benchmark Test Project, 2009).

5 'A learner's percentile rank shows how well he or she performs on a test in comparison to others' (Nassaji, 2004:118).

${ }^{6}$ In this study, 'deviation' refers to those MWUs which were in some way problematic, while 'errors' refers to each way in which such MWUs were deviant. The study investigated the acceptability of errors in collocations and discussed all types of errors, whether grammatical or lexical, but only those which were integral to the MWU itself. In other words, it considered the verb and the noun elements of the collocation and the particles immediately following the noun (Scheepers, 2014: 172).

${ }^{7}$ A negative correlation means that as one of the variables increases, the other tends to decrease, and vice versa (Flom, 2013).

\section{REFERENCES}

AKBARIAN, I. 2010. The relationship between vocabulary size and depth for ESP/EAP learners. System, 38:391-401.

ALTENBERG, B \& S Granger. 2001. The grammatical and lexical patterning of MAKE in native and non-native student writing. Applied Linguistics, 22(2):173-195.

BAHNS, J \& M ELDAW. 1993. Should we teach EFL students collocations? System, 21(1):101-114.

BAHRAMLOU, K \& H YAZDANI. 2013. Using vocabulary profiles to predict academic achievement. The Iranian EFL Journal, 9(5):265-281.

BOERS, F, J EYKMANS, J KAPPEL, H STENGERS \& M DEMECHELEER. 2006. Formulaic sequences and perceived oral proficiency: putting a lexical approach to the test. Language Teaching Research, 10(3):245-261.

COBB, T. 2000. VocabProfile. The compleat lexical tutor. Available from http://www.lextutor.ca [Accessed: 14 November 2018]

COOPER, PA. 1999. Lexis and the undergraduate: analysing needs, proficiencies and problems. Unpublished MA dissertation, University of South Africa, Pretoria.

COOPER, PA. 2000. Academic vocabulary: putting words in academic texts in perspective. South African Journal of Linguistics, Supplement 37:18-32.

COXHEAD, A. 2000. A new academic wordlist. TESOL Quarterly, 34(2):213-238.

DÖRNYEI, Z. 2007. Research methods in applied linguistics: quantitative, qualitative, and mixed methodologies. Oxford: Oxford University Press.

FAN, M. 2009. An exploratory study of collocational use by ESL students: a task based approach. System, 37:110-123.

FARGHAL, M \& H OBIEDAT. 1995. Collocations: a neglected variable in EFL. International Review of Applied Linguistics in Language Teaching, 33:315-331.

FLOM, P. 2013. How to interpret correlations with negative numbers in SPSS. Available from https://stats.stackexchange.com/questions/54455/how-to-interpret-correlations-with-negativenumbers-in-spss [Accessed: 14 November 2018].

GLEDHILL, C. 2000. The discourse function of collocation in research article introductions. English for Specific Purposes, 19:115-135. 
GRANGER, S. 1998. Prefabricated patterns in advanced EFL writing: collocations and formulae. In Cowie, AP (Ed.), Phraseology: theory, analysis and applications. Oxford: Clarendon Press. 145160.

HANCIOĞLU, N, S NEUFELD \& J ELDRIDGE. 2008. Through the looking glass and into the land of lexico-grammar. English for Specific Purposes, 27:459-479.

HAZENBERG, S \& JH HULSTIJN. 1996. Defining a minimal receptive second-language vocabulary for non-native university students: an empirical investigation. Applied Linguistics, 17(2):145-163.

HILL, J. 1999. Collocational competence. ETP, 11:4-7.

HOWARTH, P. 1998. The phraseology of learners' academic writing. In Cowie, AP (Ed.), Phraseology: theory, analysis and applications. Oxford: Clarendon Press. 161-186.

LAUFER, B. 1991. The development of L2 lexis in the expression of the advanced learner. The Modern Language Journal, 75(4):440-448.

LAUFER, B. 1992. How much lexis is necessary for reading comprehension? In Arnaud, PJL \& H Bejoint (Eds), Vocabulary and applied linguistics. London: Macmillan. 126-132.

LAUFER, B. 1997. The lexical plight in second language reading: words you don't know, words you think you know, and words you can't guess. In Coady, J \& T Huckin (Eds), Second language vocabulary acquisition: a rationale for pedagogy. Cambridge: Cambridge University Press. 20-34.

LAUFER, B \& ISP NATION. 1995. Vocabulary size and use: lexical richness in L2 written production. Applied Linguistics, 16(3):307-322.

LAUFER, B \& ISP NATION. 1999. A vocabulary-size test of controlled productive ability. Language Testing, 16(1):33-51.

LAUFER, B \& GC RAVENHORST-KALOVSKI. 2010. Lexical threshold revisited: lexical text coverage, learners' vocabulary size and reading comprehension. Reading in a Foreign Language, 22(1):5-30.

LAUFER, B \& T WALDMAN. 2011. Verb-noun collocations in second language writing: a corpus analysis of learners' English. Language Learning, 61(2):647-672.

LEE, DYW \& SX CHEN. 2009. Making a bigger deal of the smaller words: function words and other key items in research writing by Chinese learners. Journal of Second Language Writing, 18:149-165.

MACHET, M \& L TIEMENSMA. 2009. Literacy environment in support of the development of literacy skills and voluntary reading. Mousaion, 27(2):58-76.

MEIER, C. 2011. The Foundations for Learning Campaign: helping hand or hurdle? South African Journal of Education, 31:549-560.

MILTON, J \& J TREFFERS-DALLER. 2011. Vocabulary revisited: an analysis of word knowledge of undergraduate students and its relationship with academic achievement. Paper presented at CRELLA (Centre for Research in English Language Learning and Assessment) Winter Research Seminar, 15 December 2011. Available from http://www.beds.ac.uk/_data/assets/pdf_file/0020/191027/jenine-treffers-daller.pdf [Accessed: 24 October 2013].

MILTON, J \& J TREFFERS-DALLER. 2013. Vocabulary size revisited: the link between vocabulary size and academic achievement. Applied Linguistics Review, 4(1):151-172.

MORRIS, L \& T COBB. 2004. Vocabulary profiles as predictors of the academic performance of Teaching English as a Second Language trainees. System, 32:75-87.

NASSAJI, H. 2004. The relationship between depth of vocabulary knowledge and L2 learners' lexical inferencing strategy use and success. The Canadian Modern Language Review / La revue canadienne des langues vivantes, September, 61(1):107-134.

NATION, ISP. 1983. Testing and teaching vocabulary. Guidelines, 5:12-15.

NATION, ISP. 1993. Vocabulary size, growth and use. In Schreuder, R \& B Weltens (Eds), The bilingual lexicon. Amsterdam: John Benjamins. 115-134. 
NATION, ISP. 2001. Using small corpora to investigate learner needs: two vocabulary research tools. In Ghadessy, M, A Henry \& RL Roseberry (Eds), Small corpus studies and ELT: theory and practice. Amsterdam: John Benjamins. 32-45.

NATION, ISP. 2006. How large a vocabulary is needed for reading and listening? The Canadian Modern Language Review/La Revue canadienne des langues vivantes, September, 63(1): 59-82.

NATION, ISP \& R WARING. 1997. Vocabulary size, text coverage and word lists. In Schmitt, N \& M McCarthy (Eds), Vocabulary: description, acquisition and pedagogy. Cambridge: Cambridge University Press. 6-19.

NATIONAL BENCHMARK TESTS PROJECT (NBT) 2009. A national service to Higher Education. Available from http://www.pmg.org.za/files/docs/090819hesa-edit.pdf [Accessed: 4 June 2014.]

NESSELHAUF, N. 2003. The use of collocations by advanced learners of English and some implications for teaching. Applied Linguistics, 24(2):223-242.

NESSELHAUF, N. 2004. How learner corpus analysis can contribute to language teaching: a study of support verb constructions. In Aston, G, S Bernardini \& D Stewart (Eds), Corpora and language learners. Amsterdam/Philadelphia: John Benjamins. 109-124.

NESSELHAUF, N. 2005. Collocations in a learner corpus. Amsterdam: John Benjamins.

NIZONKIZA, D. 2011.The relationship between lexical competence, collocational competence, and second language proficiency. English Text Construction, 4(1):113-146. DOI: https://doi.org/10.1075/etc.4.1.06niz

NIZONKIZA, D. 2012. Quantifying controlled productive knowledge of collocations across proficiency and word frequency levels. Studies in Second Language Learning and Teaching, 2(1):67-92.

NIZONKIZA, D \& K VAN DE POEL. 2016. Testing controlled productive knowledge of adverb-verb collocations in junior researchers using English as a foreign language. Stellenbosch Papers in Linguistics, 46:99-119. DOI: https://doi.org/10.5774/46-0-235

NIZONKIZA, D \& T VAN DYK. 2015. Academic literacy of South African higher education level students: does vocabulary size matter? Stellenbosch Papers in Linguistics, 44:147-174.

NIZONKIZA, D, T VAN DYK \& H LOUW. 2013. First-year university students' productive knowledge of collocations. Stellenbosch Papers in Linguistics Plus, 42:165-181.

PAQUOT, M. 2010. Academic vocabulary in learner writing: from extraction to analysis. London: Continuum.

PRETORIUS, EJ. 2002 Reading ability and academic performance in South Africa: Are we fiddling while Rome is burning? Language Matters, 33(1):169-196. DOI: https://doi.org/10.1080/10228190208566183

QIAN, DD. 1998. Depth of vocabulary knowledge: assessing its role in adults' reading comprehension in English as a second language. $\mathrm{PhD}$ thesis, University of Toronto, Toronto.

QIAN, DD. 2002. Investigating the relationship between vocabulary knowledge and academic reading performance: an assessment performance. Language Learning, 52(3):513-536.

QIAN, D \& M SCHEDL. 2004. Evaluation of an in-depth vocabulary knowledge measure for assessing reading performance. Language Testing, 21(1):28-52.

QING, M. 2009. Second language vocabulary acquisition. Bern, Switzerland: Peter Lang.

READ, J. 2004. Research in teaching vocabulary. Annual Review of Applied Linguistics, 24:146-161.

READ, J. 2007. Second language vocabulary assessment: current practices and new directions. International Journal of English Studies, 7(2):105-125.

SCHEEPERS, RA. 2014. Lexical levels and formulaic language: an exploration of undergraduate students' vocabulary and written production of delexical multiword units. Unpublished doctoral dissertation, University of South Africa, Pretoria.

SCHEEPERS, RA. 2016. The importance of vocabulary at tertiary level. Journal for Language Teaching, 50(1):53-77. 
SCHEEPERS, RA. 2017. South African students' use of delexical multiword units: the trouble with highfrequency verbs. Stellenbosch Papers in Linguistics, 47:89-114. DOI: https://doi.org/10.5842/47-0$\underline{263}$

SCHMITT, N \& D SCHMITT. 2014. A reassessment of frequency and vocabulary size in 12 vocabulary teaching. Language Teaching, 47: 484-503.

SCHMITT, N, D SCHMITT \& C CLAPHAM. 2001. Developing and exploring the behaviour of two new versions of the Vocabulary Levels Test. Language Testing, 18(1):55-88.

SCHMITT, N \& CB ZIMMERMAN. 2002. Derivative word forms: what do learners know? TESOL Quarterly, 36(2):145-171.

SCOTT, M. 2008. WordSmith Tools version 5. Liverpool: Lexical Analysis Software.

SHIN, D \& P NATION. 2008. Beyond single words: the most frequent collocations in spoken English. ELT Journal, 62(4):339-348.

SHIRATO, J \& P STAPLETON. 2007. Comparing English vocabulary in a spoken learner corpus with a native speaker corpus: pedagogical implications arising from an empirical study in Japan. Language Teaching Research, 11(4):393-412.

STAEHR, LS. 2008. Vocabulary size and the skills of listening, reading and writing. Language Learning Journal, 36(2):139-152.

STUBBS, M. 2001. Words and phrases: corpus studies of lexical semantics. Oxford, Massachusetts: Blackwell.

VAN DYK, T. 2005. Towards providing effective academic literacy intervention. Per Linguam, 21(2):3851.

VAN DYK, T, H LOUW, D NIZONKIZA \& K VAN DE POEL. 2016. Productive knowledge of collocations may predict academic literacy, Per Linguam, 32(2):66-81. DOI: https://doi.org/10.5785/32-2-601

VERMEER, A. 2001. Breadth and depth of vocabulary in relation to L1/L2 acquisition and frequency of output. Applied Psycholinguistics, 22:217-234.

XUE, G \& ISP NATION. 1984. A university word list. Language Learning and Communication, $3(2): 215-229$.

\section{BIOGRPAHICAL NOTE}

Ruth Scheepers is a senior lecturer in the Department of English Studies at the University of South Africa (Unisa). Her research area is corpus linguistics, with a focus on collocations, and a growing interest in corpus stylistics. 